\begin{tabular}{|l|l|}
\hline & \\
&
\end{tabular}

SEÇÃO: ARTIGOS E ENSAIOS

\title{
A regulamentação das parcerias público-privadas como tática para aprofundar a privatização das universidades federais e do aparato público de ciência e tecnologia no Brasil
}

The regulation of public-private partnerships as a tactic to deep in the privatization of federal universities and the public science and technology apparatus in Brazil

João Paulo da Silva

Valdo ${ }^{1}$

orcid.org/0000-0002-1347-8228

jp.valdo@hotmail.com

\section{Juliana Iglesias Melim² orcid.org/0000-0002-3783-1700 juliana_melim@yahoo.com.br}

\section{Rafael Vieira Teixeira ${ }^{2}$} orcid.org/0000-0002-4857-3655 rafael.v.teixeira@ufes.br

Recebido em: 8 maio 2020. Aprovado em: 4 jan. 2021. Publicado em: 1 maio. 2021.
Resumo: O presente texto traz reflexões sobre as novas regulamentações que incidem sobre a gestão da educação superior pública e do aparato público de ciência, tecnologia e inovação. Trazemos, neste artigo, parte dos resultados de um estudo documental realizado sobre normas e legislações federais que afetam as universidades federais brasileiras no século XXI. Nosso percurso analitico compreende que os dispositivos legais que regulamentam as parcerias público-privadas, e principalmente o novo Marco de Ciência, Tecnologia e Inovação (Lei n. ${ }^{\circ} 13243 / 2016$ ), são táticas que aprofundam o processo de privatização da política educacional superior. Esse movimento de contrarreforma do Estado sobre o financiamento impacta na autonomia universitária e altera o papel social desempenhado pelas universidades federais brasileiras, colocando-as ainda mais a serviço do mercado. Por isso, essas modificações ocorridas no século XXI representam o aprofundamento e o aprimoramento da ofensiva neoliberal às politicas sociais, em especifico as políticas de educação superior e de ciência e tecnologia. Palavras-chave: Educação superior. Ciência. Tecnologia e Inovação. Regulamentação das parcerias público-privadas. Neoliberalismo.

Abstract: This text shares reflections on the new regulations that affect the management of public higher education and the public apparatus of science, technology and innovation. Based on documentary study on federal rules and laws that affect Brazilian federal universities since the beginning of the 21st century, our analytical path understands that the legal devices that regulate public-private partnerships, and especially the new Framework for Science, Technology, and Innovation (Law 13.243/2016), are tactics that deepen the privatization process of higher education policy. This process keeps the counter-reform of the State on financing that impacts on the university autonomy and change the social role played by Brazilian federal universities, placing the mat the service of market needs. For this reason, these changes that occurred in the 21st century represent the deepening of the direction and improvement of the neoliberal offensive to social policies, in this case, Brazilian public universities.

Keywords: Higher education. Science. Technology and Inovation. Regulation of public-private partnerships. Neoliberalism. 


\section{Introdução}

É relevante o fato de, no Brasil, a segunda década dos anos 2000 datar uma nova Lei de Carreira no Magistério Federal do Ensino Superior (Lei n 12772/12), um novo Plano Nacional de Educação (Lei no 13005/2014) e um novo Marco de Ciência, Tecnologia e Inovação (Lei nº 13243/2016). Essas Leis são parte de um conjunto que contém emendas constitucionais, leis, decretos e portarias que aprofundam a estratégia neoliberal no início dos anos 2000.

Na perspectiva que adotamos no presente texto, as alterações normativas ocorridas neste início de século expressam um processo histórico que adensa/complexifica/aprofunda o direcionamento neoliberal para as politicas sociais. Observamos que as leis referidas revogam/modificam outras que as precederam, ao mesmo tempo em que dão continuidade à concepção neoliberal, em uma perspectiva de sofisticar táticas políticas para potenciar o aparelhamento do fundo público em prol da apropriação privada tipicamente capitalista, em que pese sua face especulativa e parasitária (CARCANHOLO; NAKATANI, 1999).

O aprofundamento da contrarreforma do Estado sobre o orçamento público promove impactos importantes para a gestão e o financiamento da universidade pública, regulamentando, por exemplo, dispositivos que identificam autonomia universitária com autonomia financeira para autossustento via captação de recursos privados no mercado capitalista. Essa investida neoliberal tem consequências diversas, pois reconfigura processos de trabalho principalmente no âmbito do ensino e da pesquisa, o que, no limite, significa a redefinição do papel social da Universidade à imagem e semelhança das necessidades fetichizadas da produção/reprodução do capital em crise.

Dessa forma, o presente texto posiciona-se no sentido de assinalar a processualidade histórica a qual desemboca nas novas regulamentações que afetam a gestão da educação superior pública e do aparato público de ciência, tecnologia e inovação. O percurso analítico extrai dos dispositivos legais (inseridos neste século no arcabouço normativo do Estado brasileiro) elementos que alteram o papel social desempenhado pelas universidades federais brasileiras na divisão internacional do trabalho.

Pensar a função social da universidade requer problematizar as relações da universidade com o Estado [...]; não seria realista ignorar que muito do que é feito na universidade provém da ação do Estado (financiamento, normas curriculares, linhas de pesquisa prioritárias, fomento à $P \& D$, encadeamentos produtivos apoiados, conteúdo local etc.) (LEHER, 2018, p. 197).

A concepção de Estado acompanha elementos de fundamentação filosófica, econômica e política, repercutindo, enfim, sobre o papel social a ser desempenhado pelas universidades, notadamente as atividades de formação em nivel superior e de pesquisa e produção de conhecimentos. Nesse sentido, podemos considerar que a concepção neoliberal pressupõe que a universidade é uma instituição autossuficiente e que deve se descolar das funções de Estado para interagir com a sociedade por meio do mercado. Nessa lógica, os recursos para o financiamento das universidades públicas diriam respeito à sua própria gestão e à capacidade de seus atores institucionais captarem, via mercado, os investimentos e o custeio das atividades acadêmicas, produzindo conhecimentos e força de trabalho na forma de insumos para os diversos "nichos produtivos".

Análise recente do Banco Mundial sobre os serviços públicos e as universidades públicas brasileiras, denominado "Um ajuste justo: análise da eficiência e equidade do gasto público no Brasil", publicado em novembro do ano de 2017 , alega que as universidades federais são onerosas e elitistas, o que não justifica seus custos no contexto da "crise fiscal" (BANCO MUNDIAL, 2017).

Pode-se dizer que a concepção presente no documento do Banco Mundial é diversa daquela que a Constituinte cravou no Art. 207 da Constituição Federal de 1988. Nesta, o financiamento público estatal, a autonomia acadêmico-científica e de gestão financeira, e a unidade entre ensino, pesquisa e extensão constituem diretrizes que implicam à universidade uma função social voltada aos interesses gerais. Esse pressuposto evidentemente colide com a lógica particularista 
que fundamenta a concepção neoliberal.

Então, considerando sinteticamente os fundamentos que possibilitam distintas concepções que impactam na função social da universidade, podemos considerar que as novas regulamentações que regem atualmente a gestão e os processos de trabalho nas universidades estão carregadas de elementos históricos que propiciam analisar seu conteúdo e forma, apontando tendências políticas presentes na estratégia neoliberal, que podem ser retomadas posteriormente em comparação com outros paises latino-americanos.

\section{As novas regulamentações na gestão do orçamento público brasileiro e sua interface com as políticas de Educação Superior e de Ciência, Tecnologia e Inovação}

Como dito, podemos considerar que a Carta Magna expressa uma dada concepção de universidade, a qual, todavia, é permanentemente reconfigurada pela disputa entre as classes sociais e suas frações quanto à função social a ser desempenhada por essa política pública.

Com base no preceito constitucional, vejamos como está regulamentado hoje o sistema federal de ensino no Brasil, conforme especifica o Decreto Presidencial 9.235/17:

Art. $2^{\circ}[$ [... $~$ o sistema federal de ensino compreende: I - as instituições federais de ensino superior - IFES; II - as IES [Instituições de Ensino Superior] criadas e mantidas pela iniciativa privada; e III - os órgãos federais de educação superior. $\S 1^{\circ} \mathrm{As}$ IES criadas e mantidas por pessoas jurídicas de direito privado sujeitam-se ao sistema federal de ensino. $\S 2^{\circ} \mathrm{As}$ IES criadas pelo Poder Público estadual, distrital ou municipal e mantidas por pessoas juridicas de direito privado e as IES qualificadas como instituições comunitárias[...], sujeitam-se ao sistema federal de ensino. [...]§ $4^{\circ}$ As IES criadas pelo Poder Público estadual, distrital ou municipal existentes na data da promulgação da Constituição e que sejam mantidas e administradas por pessoa jurídica de direito público, ainda que não gratuitas, serão vinculadas ao respectivo sistema de ensino estadual (BRASIL, 2017).

Assim, as universidades federais são parte constitutiva do sistema, situando-se no âmbito das instituições federais de ensino superior (Ifes).
O Decreto também evidencia que as Ifes são criadas e mantidas pelo poder público, no caso a União, e têm no orçamento federal a fonte dos recursos para custeio e investimentos.

Isso posto, fica nítido que as novas regulamentações no âmbito da gestão orçamentária do Estado brasileiro impactam direta ou indiretamente no financiamento das universidades federais. Vejamos algumas importantes novidades trazidas pelas normas que entraram em vigência já na segunda década do século XXI, bem como suas interfaces com a gestão e a autonomia universitárias.

Segundo Castelo (2017), desde os primeiros anos da década de 1990 iniciou-se a elaboração de um conjunto de leis promovidas pelas classes dominantes no parlamento nacional, para construir a base jurídica do novo padrão de reprodução do capital. O autor destaca que o Estado definiu como prioridade máxima o pagamento dos juros e amortizações da dívida pública, garantindo altas taxas de rentabilidade para os setores rentistas das classes dominantes.

Esse imperativo implicou, por exemplo, a quebra de um princípio constitucional fundamental para o financiamento dos direitos sociais, que era a vinculação da fonte de arrecadação como um dispositivo incluso pelo constituinte para assegurar recursos para as politicas sociais, dentre as quais a educação. Porém, a correlação de forças mediada pela hegemonia neoliberal interpôs a tática da desvinculação, com intuito de direcionar os recursos do Fundo Público principalmente para a apropriação privada pelas frações rentistas do capital.

Nessa direção, a Desvinculação das Receitas da União (DRU) - criada em 1994 sob o nome Fundo Social de Emergência - tornou-se política permanente de Estado com a Emenda Constitucional (EC) 27/2000, sendo consolidada e aprofundada sucessivamente por meio das EC 42/2003, 56/2007, 59/2009, 68/2011, e culminando na significativa ampliação percentual e temporal regulamentada pela EC 93/2016. Esta última Emenda, editada já na segunda década do século XXI, trouxe uma importante "atualização": de maneira inédita, prorrogou-se a DRU por oito anos e ampliou-se de $20 \%$ para $30 \%$ o montante do orçamento público 
desvinculado das contribuições sociais fixadas pela Constituição Federal de 1988.

Art. $1^{\circ} \mathrm{O}$ art. 76 do Ato das Disposições Constitucionais Transitórias passa a vigorar com a seguinte redação: "Art. 76. São desvinculados de órgão, fundo ou despesa, até 31 de dezembro de 2023, 30\% (trinta por cento) da arrecadação da União relativa às contribuições sociais [...]" (BRASIL, 2016).

Analisamos a prorrogação (oito anos) e o aumento significativo (de $20 \%$ para $30 \%$ ) da DRU como um elemento que demarca a intencionalidade de perpetuar e aprofundar a plataforma neoliberal no âmbito do Estado brasileiro, o que guarda intima relação com a durabilidade e profundidade da atual crise do capital. Isto é, a reprodução do capital em meio à crise estrutural vem exigindo mais recursos do Fundo Público para a remuneração dos segmentos especulativos e parasitários, com impacto determinante para a gestão e o financiamento das políticas sociais, dentre as quais se encontram as universidades federais. É nesse sentido que as novas normas editadas no século XXI nos permitem analisar a sofisticação das táticas neoliberais.

[...] aumentou a prioridade ao capital financeiro e mais instrumentos do neoliberalismo foram aplicados para pagar a dívida pública e ampliar a rentabilidade do capital, através de uma política de saque às riquezas nacionais e aos direitos dos trabalhadores [...]. Em 2016, o aumento oficial da divida pública foi de $11,4 \%$. [...] ampliou-se o pagamento da divida, tanto em 2016 quanto em 2017 [...]. [...] a ampliação da DRU [...] de $20 \%$ para $30 \%$ tem o objetivo principal de aumentar esse pagamento, desviando recursos de políticas sociais e da Previdência Social (ALMEIDA; FURTADO, 2017, p. 12).

Outro dispositivo legal que corrobora nossa linha de análise é a EC 95/2016, que instituiu um "novo regime fiscal" como forma de regular o uso do Fundo Público. Esae adendo constitucional expressa o aprofundamento do caráter classista do Estado no direcionamento dos recursos do orçamento para o rentismo financeiro. A legislação limita às correções inflacionárias as chamadas "despesas primárias", que são todas as despesas não partícipes dos encargos com a divida pública: "É importante lembrar que as despesas primárias compõem todos os gastos públicos, exceto o pagamento de juros, serviços e amortizações da dívida pública que, com a Emenda, fica protegido de qualquer corte e limitação futura" (LEHER, 2018, p. 12).

Conhecida como "Teto dos Gastos", essa EC acrescenta os artigos 106 a 114 às disposições constitucionais transitórias, fixando limites individualizados para as despesas primárias nos 20 exercícios financeiros subsequentes. Ou seja, o teto de projeção das "despesas primárias" foi limitado às correções inflacionárias pelo menos até $\mathrm{o}$ ano 2037. Nos parágrafos $3^{\circ}$ a $5^{\circ}$ do artigo 107 ficam estabelecidos a forma de orçamentação e os limites para que as despesas primárias não excedam o teto fixado no referido caput.

Na prática, significa diminuição dos gastos sociais em razão direta da elevação dos encargos do orçamento público com a rolagem e o pagamento de juros que movem a especulação parasitária. Consequentemente, os seus efeitos se fazem sentir cada vez mais na contenção dos "gastos sociais", donde vêm os recursos que garantem o funcionamento das universidades federais.

Precisamente, o custeio e os investimentos realizados nas universidades federais advêm das despesas primárias vinculadas ao Poder Executivo, as quais possuem caráter discricionário, mas que foram rigidamente limitados pelo teto dos gastos estabelecido com essa EC. Com isso, é possivel afirmar que a concepção e gestão das prioridades orçamentárias têm relação direta com o conteúdo e a forma das políticas sociais, sendo que atualmente prevalece a concepção neoliberal aprofundada pelas EC 93 e 95/2016, com severo impacto sobre as universidades federais.

O orçamento das universidades federais de 2017 foi reduzido em aproximadamente 14\% em relação ao ano anterior. [...] E, mesmo após forte queda orçamentária em 2017, o Projeto de Lei Orçamentária de 2018 não corrigiu as perdas acumuladas nas despesas de custeio, e os recursos do Tesouro para capital foram reduzidos em mais de 50\% em relação ao já encolhido orçamento do ano anterior. [...] Ocorreram mudanças na estrutura do Ministério que enfraqueceram os órgãos de fomento e, [...] o sufocamento orçamentário das universidades federais não foi revertido. [...] Os cortes provocados pela mudança constitu- 
cional, estimados em $0,75 \%$ do PIB em 2017 (e, mantido o ritmo, de 7.5\% do PIB em dez anos), alcançaram a ciência, as universidades e os investimentos de modo direto e inclemente (LEHER, 2018, p. 69).

Como adverte Leher, a Emenda Constitucional nº 95/2016 não assegura a existência das universidades federais nos moldes até então instituidos, requerendo outras mudanças legais que lhe garantam exequibilidade, isto é, reconfigurando a função social da universidade por meio da forma de financiamento das suas principais atividades. Assim, com o congelamento das "despesas primárias" por 20 anos, são recolocados em pauta, por exemplo, a extinção das vinculações constitucionais obrigatórias para a educação e o fim da gratuidade nas universidades públicas: "em um par de anos não haverá recursos discricionários e, com isso, o processo de desconstituição das universidades públicas será ainda mais acelerado" (LEHER, 2018, p. 195).

O Sindicato Nacional dos Docentes das Instituições de Ensino Superior (Andes-SN) tem publicado sistematicamente dados e análises que mostram os cortes e restrições orçamentários impactando as atividades fundamentais necessárias para o funcionamento das universidades federais:

A partir de 2017, a EC 95/16 mostrou mais claramente sua natureza devastadora nos cortes de verbas para o ensino superior público e para o complexo público de ciência e tecnologia (C\&T) [...]. Por falta de pagamento, em várias universidades federais houve corte de luz, suspensão de contratos por fornecedores e de serviços terceirizados, paralisação [sic] de obras e desmantelamento da política de assistência estudantil (ANDES-SN, 2018, p. 16).

Em síntese, não se pode pensar as universidades sem analisar as determinações econômicas que, pela regulamentação no âmbito do Estado e do orçamento público, regem a gestão e as prioridades de financiamento das políticas sociais. No caso brasileiro, pode-se afirmar que as novas regulamentações não apontam para a formação de excelência, a pesquisa autônoma e a produção de conhecimento socialmente útil, princípios que dão sustentação a uma perspectiva pública de universidade.

A ação dos [...] aparelhos hegemônicos busca adaptar as relações de produção às profundas mudanças na economia global acentuando a superexploração do trabalho, promovendo novas expropriações, extinguindo estruturas de direitos estabelecidos na Constituição de 1988 e hiperdimensionando a canalização do fundo público para atender interesses econômicos do bloco de poder. É forçoso reconhecer que, após 30 anos de sua promulgação, a dimensão social da Constituição de 1988 está em frangalhos (LEHER, 2018, p. 16).

O ataque neoliberal à autonomia de gestão financeira das universidades federais e o avanço tático na regulamentação das parcerias público-privadas

Como vimos, a programática neoliberal busca fomentar modelos de financiamento das atividades acadêmicas alternativas aos gastos discricionários oriundos do orçamento da União. Tal perspectiva, segundo Leher (2003), opõe-se radicalmente à autonomia de gestão financeira cravada no Art. 207 da Carta Magna. Por outro lado, a autonomia de gestão financeira é decisiva para assegurar o caráter público da universidade e de suas ações. Isto é, o financiamento público-estatal é indispensável para prover infraestrutura, custeio e investimento nas universidades federais.

É precisamente a autonomia de gestão financeira que vem sendo tensionada pelo mote neoliberal da "autonomia financeira", cuja concepção de "autonomia pode ser identificada com o mercado, como autonomia diante do Estado para interagir livremente no mercado" (LEHER, 2003). Em outros termos, prevalece na estratégia neoliberal uma visão mais estrita, pragmática e aparentemente autônoma, que consiste em transformar a universidade em uma instituição captadora-empreendedora. A noção de autonomia financeira significa, em oposição à autonomia de gestão financeira, que a universidade atue sem limites na esfera mercantil, ampliando sua capacidade de diversificar sua fonte de financiamento/captação de recurso no setor privado.

Todavia, é possivel afirmar que a vinculação do financiamento das atividades acadêmicas às possibilidades de captação de recursos em moldes estritamente mercantis termina por subordinar a formação profissional dos trabalhadores e a pro- 
dução de conhecimento aos interesses particulares e imediatamente úteis para quem financia tais atividades. Assim, podemos dizer que a aparente autonomia, a rigor, significa heteronomia.

Isso posto, passamos a analisar a estratégia neoliberal e as suas táticas para minar a autonomia acadêmica e de gestão financeira, imprimindo ações que concretamente dão vazão à "autonomia financeira" nas universidades públicas. Neste texto alcançamos o entendimento de que o neoliberalismo tem na regulamentação das parcerias público-privadas um elemento tático central para tencionar a autonomia universitária na direção dos interesses particulares, conforme as necessidades de reprodução do capital em crise.

O aprimoramento dessa tática nas duas primeiras décadas do século XXI pode ser verificado no âmbito do Estado brasileiro por meio das novas regulamentações que incidem sobre as políticas públicas de educação superior e de ciência e tecnologia. Mediante um conjunto de normativas que regulamentaram a parceria público-privada na gestão das políticas públicas, constituiu-se a base legal para um Plano Nacional de Educação (Lei no 13.005/2014) e um Marco de Ciência, Tecnologia e Inovação (Lei n 13.243/2016), essencialmente marcado pela desconstituição do caráter autônomo da formação e da pesquisa realizadas nas universidades federais brasileiras.

Sob esse prisma, é necessário considerar que a arregimentação das parcerias público-privadas no Brasil segue uma processualidade histórica, adquirindo contornos mais definidos na estrutura estatal no começo do século XXI. Contudo, é possivel perceber que, desde a Constituição e de as suas normas complementares, já estavam iniciadas as bases legais para o processo de mercantilização almejado pela vertente neoliberal, porém ainda não necessariamente sob a forma de parcerias público-privada, pois "A LDB [Lei de Diretrizes e Bases da Educação 9.394/96], apesar de reconhecer a posição peculiar da universidade no campo da administração indireta, não garante as fontes financeiras para assegurar a autonomia" (LEHER, 2003, p. 815).

Assim, o ataque neoliberal à autonomia universitária, quanto ao financiamento público, teria como alvo as formas de provisionamento das atividades de ensino, pesquisa e extensão nas universidades públicas. Embora o Art. 54 da Lei n 9.394/96 autorize as universidades a proporem autonomamente o seu orçamento anual e plurianual, a discricionariedade da alocação de recursos compete ao respectivo "Poder mantenedor" (inciso III). Ou seja, os critérios para elaboração das propostas orçamentárias anuais pelas universidades federais seriam regulamentados via decreto presidencial (vigendo atualmente o Dec. $n^{\circ} 7.233 / 2010$ ), portanto à margem da autonomia universitária, já desde a década de 1990.

Então, o ajuste neoliberal na última década do século XX esteve marcado pelo mote da contenção do financiamento público e da regulamentação da educação superior enquanto um negócio no mercado de serviços. Conforme analisou Leher, na passagem às primeiras décadas do século vigente, "[...] a influência dos setores econômicos e de segmentos particularistas da academia assumiu ainda maiores proporções. Em suma, o sistema de fomento do que é dado a pensar se manteve fora do alcance da autonomia universitária" (LEHER, 2018, p. 145).

Estando restrito o caráter público das universidades bem como o seu financiamento estatal, ampliaram-se as condições para imprimir-lhe um conteúdo mercantil. Todavia, não se tratou de meramente transferir toda a responsabilidade e a estrutura para a esfera do mercado.

Esta forma clássica de transferência de proprie-
dade do patrimônio estatal continua sendo uma
estratégia central na politica dos diversos gover-
nos, hoje combinada com formas não clássicas
l...] de privatização: as parcerias público-privadas,
as Organizações Sociais (OS), [...] e as Fundações
ditas "de apoio" (ANDES, 2018, p. 72, grifo nosso).

Assim, a diversificação das fontes de financiamento foi um eixo fundamental na conformação das parcerias público-privadas como "formas não clássicas" de privatização. Dispositivos como os contratos de gestão, as fundações de direito privado, ditas de apoio, e os convênios com o setor privado, complexificaram a função social da universidade, aproximando-a das necessidades imediatas da acumulação capitalista em crise. 
Na área educacional, a criação de condições legais para o livre fornecimento privado e para o direcionamento das instituições públicas para a esfera privada, por meio de fundações privadas, contratos, convênios com o setor empresarial, é tão ou mais importante do que a venda da participação estatal [...] O eixo desta política, no presente momento, não é a transferência das instituições públicas para mantenedoras privadas [...] mas a implementação de um determinado modelo de autonomia, em moldes neoliberais, para que o poder do mercado possa, ele mesmo, determinar todas as dimensões da universidade: cursos, tempo, trabalho, docência, pesquisa, etc. (LEHER, 2003, p. 8-9).

Esses elementos, associados a algumas análises de experiências neoliberais já existentes em alguns paises, fizeram com que, na passagem aos anos 2000, a estratégia neoliberal buscasse maiores precisão e adesão à sua plataforma de reformas para o Estado e as políticas sociais. Conforme anota Leher (2018, p. 19): "Entre 2003 e 2014 houve relativa coesão do bloco no poder em torno da agenda macroeconômica, das políticas de alivio à pobreza e do modus operandi da contenção social manejada [...]" (LEHER, 2018, p. 19).

A nova fase das reformas para a educação superior mantém a ampliação do mercado educacional como prioridade, mas a expansão da oferta pública passa a ter uma função importante no âmbito da reprodução do capital em países dependentes. De certa forma, as universidades públicas estatais deixam de ser vistas meramente como concorrentes do negócio educacional.

Mantém-se a confiança no mercado. Reconhece sua intrinseca necessidade objetiva de busca de lucro. Mas já não se o vê como solução para todas as demandas de expansão da Educação Superior [sic] e afirma-se a exigência do concurso do Poder Público (SGUISSARDI, 2014, p. 108).

As explicações podem ser remetidas a alguns fatos: a) à brutal liberalização do mercado educacional na década de 1990, com a consequente mercantilização da educação superior, que elevou a oferta a patamares insustentáveis em relação à demanda. No final da década, houve saturação de uma parte da oferta de cursos de graduação, além da reduzida capacidade de alguns individuos contratantes arcarem com os altos custos de mensalidades e materiais; b) às necessidades de reprodução e competitividade do capital produtivo em um país dependente como o Brasil, em que as empresas não investem em núcleos de pesquisa e desenvolvimento (P\&D) próprios. Ou seja, a pesquisa e a inovação dependem de recursos (materiais e humanos) estatais existentes nas universidades e institutos públicos de pesquisa; e c) à formação em algumas áreas cuja oferta demanda alto investimento, o que desestimula setores menos competitivos do mercado educacional. Trata-se, especialmente, de expensas com pessoal e infraestrutura, como no caso de expertise e alta titulação de docentes e técnicos, e de hospitais-escola, laboratórios tecnológicos etc. Em geral, essas áreas tendem a uma oferta aquém das necessidades de formação requisitadas pelo mercado de trabalho, o que justifica um gasto público altamente seletivo; 4) à ampliação do acesso à educação superior no âmbito das estratégias de "combate à pobreza".

\begin{abstract}
No caso particular da educação superior brasileira, o Estado impulsionou a expansão provisória do sistema público com uma precarização permanente (o Reuni) enquanto direcionou bilhões de reais na forma de isenções fiscais (Prouni) e de créditos educacionais (Fies) para o setor privado, ocasionando a manutenção de $75 \%$ das matriculas no ensino privado e a gigantesca concentração e centralização de capitais, muitos deles transacionados nas bolsas de valores e com presença acentuada de empresas estrangeiras. É o aprofundamento de mais uma frente de acumulação para o capital em crise, proporcionando a consolidação da lógica rentista do capital [...] Como bem resume Juliana Fiuza Cislaghi (2012, p. 282), "I...] as universidades públicas, mais do que nunca, se mercantilizam no mesmo processo pelo qual passam as demais politicas sociais, geridas e financiadas num mix público-privado (sic)" (CASTELO, 2017, p. 63).
\end{abstract}

Nota-se que, nas universidades públicas, sobretudo as federais, a tarefa assumida pelos governos neoliberais foi adequá-las ao modelo de gestão de e para o mercado, contendo recursos ditos desnecessários e diferenciando o seu direcionamento de acordo com critérios de produtividade, aumentando a produtividade do trabalho e focalizando a expansão dos cursos de acordo com as necessidades do mercado de trabalho, entendido como parte das "estratégias de combate à pobreza". Nesse sentido, 
[...] a diversificação do sistema é vigorosamente defendida, pois, em geral, vem acompanhada de novos provedores privados e, não menos importante, permite a adequação do ensino superior ao mercado e aos segmentos sociais: universidades com núcleos de excelência, para formar as classes superiores e prestar serviços tecnológicos e políticos ao mercado; universidades de ensino, para formar profissionais liberais e técnicos, basicamente provenientes das classes médias; centros universitários e faculdades isoladas, para formar profissionais de pouca especialização, provenientes das classes média-baixa e média, e escolas profissionalizantes para egressos do ensino médio ou fundamental vindos das classes subalternas (LEHER, 2003, p. 12).

Diante do exposto, é possivel afirmar que a diversificação do sistema provoca a crescente diferenciação das instituições e dos seus respectivos propósitos. Essa premissa vincula ainda mais a produtividade acadêmica à lógica mercantil, impactando a função social da universidade. 0 que se põe no horizonte é uma distinção crescente entre as universidades de pesquisa e os "escolões de ensino terciário".3

Essa diferenciação aprofunda a concorrência não apenas entre as instituições, mas entre áreas de conhecimento, setores de uma mesma instituição e até mesmo entre colegas de trabalho de uma mesma unidade acadêmica.

[...] essa dinâmica do poder, em que alguns grupos se apossam de temas e recursos, pode, também, ser gerada pela política de financiar centros de excelência, o que tende a significar uma estratégia de cooptação de algumas instituições em detrimento da emancipação do sistema universitário como um todo. Tratase de uma estratégia de poder do Estado. [...] concorrer, ou disputar as verbas liberadas por projetos [...] traduz-se numa busca de autonomia por cooptação e [...] estimula uma dinâmica de "competição administrada", na qual é conveniente que departamentos e institutos concorram entre si pelas verbas e pelo sucesso, "o que significa professores e estudantes disputando [...]". [...] convém, de certo modo, "que todos sejam mal aquinhoados, para sentirem, na devida medida, a importância da disputa [...] (LEMOS, 2011, p. 116)
A combinação entre as formas clássicas e não clássicas de privatização demonstra a sofisticação e o aprofundamento da estratégia neoliberal, complexificando a relação entre interesses públicos e privados. Em termos da formulação do conceito de parceria público-privada, salta aos olhos o protagonismo do Banco Mundial:

\begin{abstract}
O Handbook on PPP and Education ("Manual de parcerias público-privadas e educação") constitui uma das publicações pioneiras nesse campo, balizando a orientação e os investimentos desse braço do BM na educação. Sendo a educação terciária o setor educacional privilegiado para o estabelecimento de parcerias público-privadas e para o desenvolvimento da atuação privada no mundo todo, a América Latina e o Caribe se destacam como espaços particularmente promissores desse desenvolvimento [...] (PRONKO, 2014, p. 102).
\end{abstract}

Conforme destaca a autora, a partir dos anos 2000 ampliou-se consideravelmente a difusão das parcerias público-privadas, sendo a forma privilegiada de atuação no campo educacional. Esse segmento, inclusive, vem recebendo aumento significativo do volume de recursos emprestados diretamente pelo BM (via Corporação Financeira Internacional - CFI) ou por instituições por ele apoiadas.

Hoje o investimento em educação constitui estratégia prioritária do CFI, justificada nos seguintes objetivos: - ampliar o acesso à educação de qualidade para grupos de média e baixa renda, aumentando, assim, a mobilidade social; • introduzir formas inovadoras de financiamento/prestação de serviços; · melhorar os padrões de qualidade e eficiência; · facilitar o intercâmbio internacional de melhores práticas; - ajudar os alunos/instituições a obter acesso a financiamento; $\cdot$ proporcionar oportunidades de trabalho para profissionais qualificados; · complementar o setor público, a fim de atingir objetivos nacionais em matéria de educação (CORPORAÇÃO FINANCEIRA INTERNACIONAL apud PRONKO, 2014, p. 103, grifo nosso).

No tocante às regulamentações que incidem sobre as universidades federais e o aparato público de ciência e tecnologia no país, de uma forma mais abrangente, podemos destacar um conjunto de

\footnotetext{
3 De acordo com Marcela Pronko, o Banco Mundial inseriu esse termo no âmbito das reformas educacionais para tratar a educação superior como parte das estratégias de combate à pobreza. Sob essa denominação, fortalece-se a diversificação e a diferenciação no ensino superior, já que passa a ser visto como extensão dos demais niveis do sistema educacional, desobrigando-se a indissociabilidade entre ensino, pesquisa e extensão. Segundo a autora, a linha argumentativa passa pelo discurso da "[...] eficácia do gasto público. Essa diretriz de política, encampada pelo BM na década de 1990, levaria à reconfiguração do campo da educação superior, transformado agora em educação 'terciária', espaço por excelência para a constituição de 'quase-mercados', mediante uma nova forma de gestão: a parceria público-privada em educação" (PRONKO, 2014, p. 96).
} 
normativas que alargam e aplainam o terreno para aprimorar a simbiose entre as funções estatais financiadas pelo fundo público e os interesses privados constitutivos do mercado capitalista, favorecendo-os.

Um exemplo importante do avanço na regulamentação das parcerias público-privado está expresso nas Leis Federais $n^{\circ} 11.079 / 04$ e $n^{\circ}$ $12.776 / 12$ que instituem normas gerais para licitação e contratação de parceria público-privada no âmbito da administração pública. Não obstante avançar a legalidade dos contratos de parceria público-privada, trata-se de oferecer maiores garantias de pagamento ao "parceiro privado", caso o ente público venha a descumprir as suas obrigações contratuais. É assim que se justificou a criação de um Fundo Garantidor de Parcerias Público-Privadas ${ }^{4}$ patrocinado pelos entes públicos para que o ente privado não tenha qualquer risco no dispêndio de seus recursos, sendo discriminadas, inclusive, as formas pelas quais o ente privado poderá receber a integralização de suas cotas

A referida Lei aprimora, ainda, as formas pelas quais os entes privados podem se utilizar dos recursos públicos via contratos/convênios de parceria, com a possibilidade de atualização de valores e a transferência do controle ou administração temporária das sociedades (Art. $5^{\circ}$ ), além de oferecer novos incentivos aos parceiros privados (Art. 23).

Outro exemplo é a Lei n 12.349/10, que altera a Lei de licitações no 8.666/94. Esta alteração afeta diretamente as instituições federais de ensino superior (Ifes), autorizando-as a firmar convênios e contratos "[...] com fundações instituidas com a finalidade de dar apoio a projetos de ensino, pesquisa e extensão e de desenvolvimento institucional, científico e tecnológico, inclusive na gestão administrativa e financeira [...]" (Art. $3^{\circ}$ ).

Assim, vê-se que as novas regulamentações afirmam a diversificação das fontes de financiamento como forma de custear as atividades acadêmicas propriamente ditas (atividades-fim) e, inobstante, também os recursos de manutenção e melhoria de gestão infraestrutura (atividades-meio).
Vê-se que essa forma de gestão, cada vez mais presente no cotidiano das universidades federais, viabiliza a apropriação privada dos recursos e serviços públicos por meio de fundações ditas de apoio, como fica evidente no Art. $6^{\circ}$ da citada Lei de 2010: "No cumprimento das finalidades referidas nesta Lei, poderão as fundações de apoio, por meio de instrumento legal próprio, utilizar-se de bens e serviços das IFES e demais ICTs contratantes[...]" (BRASIL, 2010).

Esta Lei autoriza ainda o Fundo Nacional de Desenvolvimento Científico e Tecnológico (FNDCT) - por meio de sua secretaria executiva, a Financiadora de Estudos e Projetos (FINEP) - e os órgãos de fomento à pesquisa, como o Conselho Nacional de Desenvolvimento Científico e Tecnológico (CNPq), a firmarem convênios com as universidades e demais Ifes, por meio das fundações ditas de apoio (Art. 6\%).

Com a regulamentação citada, as universidades firmam-se enquanto organizações sociais, mesmo que por meio de uma via não clássica. Isto é, se não puderam ser formalmente transformadas em organizações sociais (devido à forte resistência popular e sindical organizada), tal como propunha o Plano Diretor da Reforma de Estado na década de 1990, na prática, as universidades federais passaram, nos anos 2000 , a funcionar como tal. Essa forma de regulamentação fragmentada que transforma tacitamente as universidades em organizações sociais é a expressão da tática neoliberal no século XXI, sob o contexto da crise estrutural. Utilizar as

[...] parcerias público-privadas em educação surgiu como uma alternativa mais palatável à privatização direta dos "serviços educacionais" promovida pelo BM. Como forma de mediação entre Estado e mercado, as parcerias público-privadas se colocavam como uma possibilidade que promovia o "melhor" das duas esferas, concentrando esforços para resolver, ao mesmo tempo, os problemas da concorrência internacional e do acesso da população aos serviços (PRONKO, 2014, p. 98).

\footnotetext{
4 Não é estranho que a processualidade da regulamentação das PPPs encontre paridade entre o âmbito geral, aqui tratado, e o específico, expresso, por exemplo, na regulamentação do Fundo de Financiamento Estudantil (FIES). Este, iniciado em 2001, atualmente goza de um fundo garantidor em prol das mantenedoras privadas. Em 2014, o FIES foi regulamentado como politica de Estado, através PNE 2014-2024 (Lei n. ${ }^{\circ}$ 13.005/2014) e regulamentado pela Portaria Normativa MEC n³/14.
} 
O principal mecanismo de gestão financeira para as parcerias são as fundações públicas de direito privado, ditas de apoio. De acordo com o Tribunal de Contas da União (apud CISLAGHI, 2012, p. 274), as fundações foram regulamentadas na década de 1990 e passaram a ser instrumentos de captação de recursos fora do orçamento, e de complementação salarial para parte dos trabalhadores das universidades, como resposta à drástica redução de recursos de custeio e ao arrocho salarial. Na primeira e na segunda década do século XXI, as fundações de apoio obtiveram enorme apreço dos poderes Executivo e Legislativo do Estado brasileiro, avançando sua regulamentação para praticamente todas as frentes de gestão das políticas sociais.

Nesse mesmo sentido, o Decreto Presidencial $n^{\circ} 7.423 / 2010$, que revogou o Decreto $n^{\circ}$ 5.205/2004, aprofunda a regulamentação da relação entre as instituições federais de educação superior e as fundações de apoio. No parágrafo único do seu Art. $1^{\circ}$, o Decreto trata da definição e do objetivo dessas fundações:

Art. $1^{\circ}$. [...] Parágrafo único. A fundação registrada e credenciada como fundação de apoio visa dar suporte a projetos de pesquisa, ensino e extensão e de desenvolvimento institucional, científico e tecnológico de interesse das instituições apoiadas e, primordialmente, ao desenvolvimento da inovação e da pesquisa científica e tecnológica, criando condições mais propícias a que as instituições apoiadas estabeleçam relações com o ambiente externo (BRASIL, 2010a).

Pode-se entender que a criação de condições mais propicias para que as Ifes estabeleçam relações com o ambiente externo se trata, exatamente, das parcerias público-privadas. A forma pela qual ocorrem as ditas parcerias via fundações passa pela contratualização (contratos e ou convênios bilaterais ou multilaterais), que, gradativamente, consolida-se como o modelo de gestão ideal para as organizações sociais, como expresso no Art. $8^{\circ}$ desta mesma norma:

[...] Art. $8^{\circ}$. As relações entre a fundação de apoio e a instituição apoiada para a realização dos projetos institucionais de que trata o $\$ 10$ do art. $6^{\circ}$ devem ser formalizadas por meio de contratos, convênios, acordos ou ajustes individualizados, com objetos específicos e prazo determinado (BRASIL, 2010a).
Assim, a privatização interna das IES públicas, transmutadas em organizações sociais, se concretiza mediante a adoção dos contratos de gestão, que inserem a lógica da gestão privada-mercantil na gestão pública-estatal, por meio de parcerias que criem condições de apoio para o desenvolvimento das atividades-fim, e de atividades-meio.

A Lei n 12.863/2013 é emblemática nesse sentido, pois amplia significativamente a possibilidade de contratualização por meio de fundações públicas de direito privado; e ainda AUTORIZA, por intermédio do parágrafo único do art. $1^{\circ}$-B, a dispensa de licitação para a identificação e escolha das empresas convenentes. Ou seja, excluem-se gradativamente os dispositivos legais que protegem os interesses públicos da sanha particularista. E a dispensa de licitação é, neste sentido, um exemplo gritante.

Ademais, a inclusão do Art. 6 na Lei de 1994 (por meio da Lei $n^{\circ} 12.863 / 13$ ) regulamenta a utilização de bens e serviços das Ifes e ICTs como contrapartida nas contratualizações efetivadas através das fundações de apoio:

Art. $6^{\circ}$ No cumprimento das finalidades referi-
das nesta Lei, poderão as fundações de apoio,
por meio de instrumento legal próprio, utilizar-
-se de bens e serviços das IFES e demais ICTs
apoiadas, pelo prazo necessário à elaboração
e execução do projeto de ensino, pesquisa e
extensão e de desenvolvimento institucional,
científico e tecnológico e de estimulo à ino-
vação, mediante ressarcimento previamente
definido para cada projeto. $\S 10$ [...] o uso de
bens e serviços das IFES ou demais ICTs po-
derá ser contabilizado como contrapartida da
instituição ao projeto [...] (BRASIL, 2013).

A forma de alienação dos bens e serviços das Ifes por meio das parcerias fica patente na citação anterior. A possibilidade de apropriação privada do aparato público, inclusive os bens imóveis e a força de trabalho altamente qualificada, está ampliada na regulamentação das parcerias público-privadas, no tocante à gestão e forma de financiamento às universidades públicas brasileiras. E fica difícil desconsiderar que esse elemento altera substantivamente o propósito da instituição universitária.

Com conteúdo muito semelhante à Lei $n^{\circ}$ 12.863/2013, o Decreto Presidencial 8.240/2014 
arregimenta de uma maneira mais acurada as PPPs nas Ifes e ICTs, por meio das fundações de apoio. É possivel perceber nesse Decreto, assim como na Lei Federal referida, certa centralidade atribuída às atividades de pesquisa no âmbito das Ifes, o que também repercute de maneira importante na autonomia e na função social da universidade pública.

Direcionado especialmente às atividades de ciência e tecnologia e à inovação tecnológica, ${ }^{5} \mathrm{O}$ Decreto 8.240/14 regulamenta os convênios e os critérios de habilitação de empresas privadas para participação no fomento das pesquisas. Tais convênios são instrumentos que preveem, no $\operatorname{Art} .1^{\circ}, \S 2^{\circ}$ :

I - [...] a transferência de recursos financeiros ou não financeiros, em parceria com entidades privadas, com ou sem fins lucrativos, envolvendo a execução de projetos de interesse reciproco, podendo contar ainda com a participação de organizações sociais, que tenham contrato de gestão firmado com a União (BRASIL, 2014).

As entidades com fins lucrativos têm acesso ao fundo público ampliado pelo Decreto, podendo propor ações em todas as áreas de atuação das universidades federais. Como vimos, no Art. $2^{\circ}$ são elencadas tais possibilidades: "Os convênios [...] terão como finalidade o financiamento ou a execução de projetos de ensino, pesquisa, extensão, desenvolvimento institucional, científico e tecnológico e estímulo à inovação" (BRASIL, 2014).

A penetração das parcerias público-privadas no arcabouço jurídico-normativo que rege as universidades federais brasileiras fica ainda mais evidente no parágrafo único do Art. $3^{\circ}$. Nele o Decreto determina que a participação de pelo menos uma Ifes (ou ICT) é indispensável para a realização dos projetos objeto dos convênios de ECTI.

Os convênios referidos no caput poderão ter tantos partícipes quanto forem necessários para a realização do projeto, sendo, indispensável, a participação de, no mínimo: I - fundação de apoio; II - IFES ou demais ICT apoiada; e III - participe de natureza diferente das anteriores. (BRASIL, 2014, grifo nosso).

Assim, podemos afirmar que esse Decreto, vigente desde 2014, assim como a Lei $n^{\circ}$ 12.863/2013, atesta o avançado estágio da regulamentação das parcerias público-privadas na gestão das universidades federais nesta segunda década de século XXI. Tal constatação nos leva, no presente texto, a reconhecer a eficácia desta tática neoliberal quanto ao redirecionamento das prioridades acadêmicas em favor dos interesses particulares. Assim, a análise do processo de arregimentação do modelo de gestão público-privado contém fundamentos importantes para análise das alterações político-econômicas contemporâneas na América Latina e impactos na política de educação, evidenciando parte deste processo no caso brasileiro.

\section{Considerações finais}

Em forma de síntese, portanto, convém destacar alguns argumentos que validam nossa linha de análise do processo de penetração da parceria público-privada como ótima forma para gestão das Ifes sob a perspectiva neoliberal: a) a regulamentação insere o trâmite institucional próprio das universidades e demais Ifes no escopo da burocracia que rege os convênios entre agentes públicos e privados (com ou sem fins de lucro). Ou significa dizer: no atual contexto as Ifes são o alvo prioritário dos convênios objeto das parcerias; 2) cabe anotar que as atividades de pesquisa, ensino, extensão e desenvolvimento institucional compõem o leque de possibilidades para os referidos convênios/contratos. Isto é, fica evidente que o modelo de gestão das Ifes é a parceria público-privada, encampando toda a gama de atividades-meio e atividades-fim das universidades; 3) porém, as atividades de pesquisa,

\footnotetext{
5 De acordo com Roberto Leher, a inovação tecnológica no âmbito das universidades é uma expressão do capitalismo dependente Nos países do G7, por exemplo, a inovação é fomentada por departamentos de Pesquisa e Desenvolvimento (P\&D) das empresas. No Brasil e demais países periféricos, diante das cadeias produtivas de baixa intensidade tecnológica, "os governos Cardoso, Lula da Silva e Dilma Rousseff elegeram as universidades como alvo das políticas que tentam atribuir à universidade o que o setor produtivo não desenvolve". A conversão das universidades no principal lócus de P\&D transforma a universidade pública em espaço de apropriação pelo capital privado, por meio das parcerias público-privadas. "A inovação e a P\&D, atividades que deveriam ser desenvolvidas no ambiente empresarial, passa a governar as prioridades da própria universidade. [...] O desenho iniciado pelo governo militar assumiu contornos mais definidos e operacionais" (LEHER, 2018, p. 191-192)
} 
principalmente em algumas áreas relacionadas à inovação, gozam de notável prioridade mediante os interesses privados (sobretudo com fins lucrativos), constituindo, de fato, a diferenciação e a diversificação como regras no modelo das parcerias; 4) a força de trabalho existente no serviço público é um dos principais focos dos interesses privados mediante este modelo de gestão. O alto nivel de formação de docentes e técnicos atrai os agentes privados, que vêm nesta forma de gestão o acesso à força de trabalho altamente qualificada sem grandes investimentos. A regulamentação dos convênios/contratos/parcerias pressupõe participantes vinculados à instituição apoiada (inciso III, $\S 1^{\circ}$, Art. $9^{\circ}$, do Dec. n 8.240/14).

Enfim, as normas editadas nas duas primeiras décadas deste século aprimoram e aprofundam o modelo de gestão por meio de convênios/contratos entre agentes públicos e privados, o que nos permite afirmar que avança a estratégia neoliberal em um contexto de novas exigências do capital em crise, redirecionando e ressignificando a função social das universidades brasileiras.

Esse processo é levado a bom termo, de modo sutil, mas extremamente eficaz, pela reforma universitária [...] que mostra a centralidade da [pesquisa e da] pós-graduação como núcleo gerador das mudanças na prática universitária, tendo no produtivismo acadêmico importante instrumento ideológico. Isto resulta [...] na radical mudança da identidade da universidade e do trabalho nela realizado, mostrando em acréscimo que o trabalho imaterial produtivo, isto é, a pesquisa aplicada, é o foco central [...] (SGUISSARDI; SILVA JUNIOR, 2018, p. 283).

Finalmente, entendemos que somente a partir da minuciosa caracterização do modelo de gestão público-privado, enquanto elemento tático da estratégia neoliberal, pode-se avançar a análise da essência do conjunto normativo que altera substantivamente a função social das universidades públicas brasileiras neste século. Compreendemos que esses fundamentos são explicativos para as principais novidades trazidas pelas Leis: n 12.772/2012 (Carreira do Magistério Federal); n 13.005/2014 (Plano Nacional de Educação 2014-2024); e n 13.243/2016 (Novo Marco de Ciência, Tecnologia e Inovação), as quais pretendemos analisar em um próximo texto a partir dos pressupostos analíticos aqui discutidos.

\section{Referências}

ALMEIDA, J.; FURTADO, M. As reformas, a universidade e a resistência popular. Universidade e Sociedade, Brasília, ano 27, n. 60, jul. 2017. ISSN 1517-1779. Semestral.

ANDES-SN (Sindicato Nacional dos Docentes das Instituições de Ensino Superior). Neoliberalismo e Política de C\&T no Brasil. Um balanço crítico (1995-2016). Cadernos ANDES, Brasília, n. 28., jan. 2018. Disponivel em: http://portal.andes.org.br/imprensa/documentos/ imp-doc-186083876.pdf. Acesso em: 18 maio 2018.

BANCO MUNDIAL. Um Ajuste Justo: Análise da eficiência e equidade do gasto público no Brasil. In: BANCO MUNDIAL. Brasil revisão das despesas públicas. Volume 1: sintese. nov. 2017. Disponivel em: http:// www.worldbank.org/pt/country/brazil/publication/ brazil-expenditure-review-report. Acesso: 18 maio 2018.

BRASIL. Decreto n 9.235, de 15 de dezembro de 2017. Dispõe sobre o exercicio das funções de regulação, supervisão e avaliação das instituições de educação superior e dos cursos superiores de graduação e de pós-graduação no sistema federal de ensino. Brasília, dez. 2017. Disponivel em: http://www.planalto.gov.br/ ccivil_03/_ato2015-2018/2017/decreto/D9235.htm. Acesso em: 15 mar. 2018

BRASIL. Emenda Constitucional $n^{\circ}$ 93, de 8 de setembro de 2016. Altera o Ato das Disposições Constitucionais Transitórias para prorrogar a desvinculação de receitas da União e estabelecer a desvinculação de receitas dos Estados, Distrito Federal e Municípios. Brasilia, 8 set. 2016. Disponivel em: http://Www.planalto.gov.br/ ccivil_03/constituicao/emendas/emc/emc93.htm. Acesso em: 15 mar. 2018.

BRASIL. Emenda Constitucional n 95 , de 15 de dezembro de 2016. Altera o Ato das Disposições Constitucionais Transitórias, para instituir o Novo Regime Fiscal, e dá outras providências. Brasilia, 15 dez. 2016a. Disponível em: http://www.planalto.gov.br/ccivil_03/constituicao/ emendas/emc/emc95.htm. Acesso em: 15 mar. 2018.

BRASIL. Decreto n 8.240, de 21 de maio de 2014. Regulamenta os convênios e os critérios de habilitação de empresas referidos no art. 10-B da Lei no 8.958, de 20 de dezembro de 1994. Brasilia, 21 maio 2014. Disponivel em: http://wwww.planalto.gov.br/ccivil_03/_Ato2011-2014/2014/ Decreto/D8240.htm\#art27. Acesso em: 15 mar. 2018.

BRASIL. Lei no 12.863 , de 24 de setembro de 2013. Altera a Lei no 12.772, de 28 de dezembro de 2012, que dispõe sobre a estruturação do Plano de Carreiras e Cargos de Magistério Federal; altera as Leis nos 11.526, de 4 de outubro de $2007,8.958$, de 20 de dezembro de 1994 . 11.892, de 29 de dezembro de 2008, 12.513, de 26 de outubro de 2011, 9.532, de 10 de dezembro de 1997, 91, de 28 de agosto de 1935, e 12.101, de 27 de novembro de 2009; revoga dispositivo da Lei no 12.550, de 15 de dezembro de 2011; e dá outras providências. Brasilia, 24 set. 2013. Disponivel em: http://www.planalto.gov. br/ccivil_03/_ato2011-2014/2013/Lei/L12863.htm. Acesso em: 15 mar. 2018 
BRASIL. Lei n 12.349, de 15 de dezembro de 2010. Altera as Leis nos 8.666, de 21 de junho de 1993, 8.958, de 20 de dezembro de 1994, e 10.973, de 2 de dezembro de 2004; e revoga o $\$ 10$ do art. 20 da Lei no 11.273 , de 6 de fevereiro de 2006. Brasilia, 15 dez. 2010. Disponivel em: http://Www.planalto.gov.br/ccivil_03/_ato20072010/2010/Lei/L12349.htm. Acesso em: 15 mar. 2018.

BRASIL. Decreto $n^{\circ} 7.423$, de 31 de dezembro de 2010. Regulamenta a Lei $n^{\circ}$ 8.958, de 20 de dezembro de 1994, que dispõe sobre as relações entre as instituições federais de ensino superior e de pesquisa científica e tecnológica e as fundações de apoio, e revoga o Decreto $n^{\circ} 5.205$, de 14 de setembro de 2004 . Brasília, 31 dez. 2010. Disponivel em: http://www.planalto.gov. br/ccivil_03/_Ato2007-2010/2010/Decreto/D7423. htm\#art16. Acesso em: 15 mar. 2018.

CARCANHOLO, R.; NAKATANI, P. O capital especulativo parasitário: uma precisão teórica sobre o capital financeiro, característico da globalização. Ensaios FEE, Porto Alegre, v. 20, n. 1, p. 284-304, jun.1999.

CASTELO, R. Supremacia rentista no Brasil neoliberal e a violência como potência econômica. Universidade e Sociedade, Brasilia, ano XXVII, n. 60, jul. 2017. ISSN 1517-1779. Semestral.

CISLAGHI, J. F. Financiamento do ensino superior no Brasil: novos e antigos mecanismos de privatização do fundo público. In: SALVADOR, Evilásio et al. (org.). Financeirização, fundo público e política social. São Paulo: Cortez, 2012

LEHER, R. Projetos e Modelos de Autonomia e Privatização das Universidades Públicas. Revista da ADUEL, Londrina, set. 2003. Disponivel em: https://sindiproladuel.org.br/wp-content/uploads/2018/05/revistaaduelset2003.pdf. Acesso: 23 jul. 2018.

LEHER, R. Universidade e heteronomia cultural no capitalismo dependente: um estudo a partir de Florestan Fernandes. Rio de Janeiro: Consequência, 2018.

LEMOS, D. Trabalho docente: tensões e contradições. Caderno CRH, Salvador, v. 24, n. 1, p. 105-120, 2011.

PRONKO, M. O Banco Mundial no campo internacional da educação. In: PEREIRA, J. M. M.; PRONKO, M. (org.). A demolição de direitos: um exame das políticas do Banco Mundial para a educação e a saúde (1980-2013). Rio de Janeiro: Escola Politécnica de Saúde Joaquim Venâncio/Fiocruz, 2014. p. 89-112.

SGUISSARDI, V. Estudo diagnóstico da politica de expansão da (e acesso à) Educação Superior no Brasil 2002-2012. Relatório de Pesquisa. Piracicaba: Mimeo, 20 set.2014. Edital nº 051/2014 SESU/MEC. Projeto de Organismo Internacional - OEI - Projeto OEI/BRA/10/002.

SGUISSARDI, V.; SILVA JUNIOR, J. dos R. Trabalho intensificado nas federais: pós-graduação e produtivismo acadêmico. 2. ed. Uberlândia: Navegando Publicações, 2018.

\section{João Paulo da Silva Valdo}

Doutorando em Serviço Social pela Universidade Federal do Rio de Janeiro (UFRJ), no Rio de Janeiro, RJ, Brasil; assistente social; integrante do Grupo de Estudos e Pesquisas em Educação e Serviço Social (GEPESS) e do Grupo de Estudos e Pesquisas sobre Questão Racial e Serviço Social (GEPEQSS), ambos vinculados a Escola de Serviço Social da UFF/Niterói, em Niterói, RJ, Brasil.

\section{Juliana Iglesias Melim}

Doutora em Serviço Social pela Universidade Federal do Rio de Janeiro (UFRJ), no Rio de Janeiro, RJ, Brasil; professora do Departamento de Serviço Social da Universidade Federal do Espírito Santo (UFES), em Vitória, ES, Brasil.

\section{Rafael Vieira Teixeira}

Doutor em Política Social pela Universidade Federal do Espírito Santo (UFES), em Vitória, ES, Brasil; professor adjunto da UFES, lotado no Departamento de Serviço Social e docente colaborador do Programa de Pós- graduação em Politica Social da mesma instituição.

\section{Endereço para correspondência}

Rafael Vieira Teixeira

Universidade Federal do Espirito Santo

Av. Fernando Ferrari, 514

Goiabeiras, 29075-910

Vitória, ES, Brasil

Os textos deste artigo foram revisados pela Poá Comunicação e submetidos para validação do(s) autor(es) antes da publicação. 